Please do not remove this page

RMIT

UNIVERSITY

\title{
Synthesis and self-assembly of polyimide/poly(dimethylsiloxane) brush triblock copolymers
}

Halim, Andri; Gurr, Paul; Blencowe, Anton; Bryant, Gary; Kentish, Sandra; Qiao, Greg

https://researchrepository.rmit.edu.au/esploro/outputs/9921861934201341/filesAndLinks?institution=61RMIT_INST\&index=null

Halim, A., Gurr, P., Blencowe, A., Bryant, G., Kentish, S., \& Qiao, G. (2013). Synthesis and self-assembly of polyimide/poly(dimethylsiloxane) brush triblock copolymers. Polymer, 54(2), 520-529.

https://doi.org/10.1016/j.polymer.2012.12.027

Document Version: Accepted Manuscript

Published Version: https://doi.org/10.1016/j.polymer.2012.12.027

Repository homepage: https://researchrepository.rmit.edu.au

(c) 2012 Elsevier Ltd. All rights reserved.

Downloaded On 2023/04/26 23:32:46 +1000

Please do not remove this page 
Thank you for downloading this document from the RMIT Research Repository.

The RMIT Research Repository is an open access database showcasing the research outputs of RMIT University researchers.

RMIT Research Repository: http://researchbank.rmit.edu.au/

\section{Citation:}

Halim, A, Gurr, P, Blencowe, A, Bryant, G, Kentish, S and Qiao, G 2013, 'Synthesis and self-assembly of polyimide/poly(dimethylsiloxane) brush triblock copolymers', Polymer, vol. 54 , no. 2 , pp. $520-529$

See this record in the RMIT Research Repository at:

http://researchbank.rmit.edu.au/view/rmit:20278

Version: Accepted Manuscript

Copyright Statement: ㄷ 2012 Elsevier Ltd. All rights reserved.

Link to Published Version:

http://dx.doi.org/10.1016/j.polymer.2012.12.027 


\title{
Synthesis and Self-assembly of Polyimide/Poly(dimethylsiloxane) Brush Triblock Copolymers
}

Andri Halim, ${ }^{1,2}$ Paul A. Gurr, ${ }^{1,2}$ Anton Blencowe, ${ }^{2}$ Sandra E. Kentish ${ }^{1}$ and Greg G. Qiao. ${ }^{1,2 *}$

${ }^{1}$ Cooperative Research Centre for Greenhouse Gas Technologies, Department of Chemical and Biomolecular Engineering, University of Melbourne, VIC 3010, Australia

${ }^{2}$ Polymer Science Group, Department of Chemical and Biomolecular Engineering, University of Melbourne, VIC 3010, Australia

* Corresponding author. Tel: +61 383 448665; fax: +61 383444153

E-mail address: gregghq@,unimelb.edu.au (G.G. Qiao)

\begin{abstract}
A series of novel brush triblock copolymers containing 'glassy' fluorinated polyimide, poly((4,4'-hexafluoroisopropylidene diphthalic anhydride)-co-(2,3,5,6-tetramethyl-1,4phenylenediamine) $\quad$ (poly(6FDA-co-TMPD)), and 'rubbery' polydimethylsiloxane monomethacrylate (PDMS-MA) were synthesized and characterized. Well-defined difunctional poly(6FDA-co-TMPD) with $\alpha, \omega$-amino end-groups was initially prepared via step-growth polymerization using precise control of the diamine (TMPD) to dianhydride (6FDA) ratio. Subsequent functionalization with 2-bromoisobutyryl bromide afforded a telechelic macroinitiator suitable for atom transfer radical polymerization (ATRP). The macroinitiator and its diamino poly(6FDA-co-TMPD) precursor were characterized via gel permeation chromatography (GPC), ${ }^{1} \mathrm{H}$ nuclear magnetic resonance (NMR) spectroscopic analysis and matrix assisted laser desorption ionization time-of-flight (MALDI ToF) mass spectroscopy. ATRP of PDMS-MA using the macroinitiator in different molar ratios afforded a series of brush triblock copolymers with high monomer conversions (88-94\%) and varying PDMS weight fractions. Self-assembly of the triblock brush copolymers in
\end{abstract}


dimethylformamide (DMF) afforded 'nano-flower' shaped micelles with hydrodynamic diameters $\left(\mathrm{d}_{\mathrm{H}}\right)$ ranging from 87 to $109 \mathrm{~nm}$, as determined by dynamic light scattering (DLS) analysis. Cross-linking of the micelles was achieved via hydrogen abstraction through the thermal degradation of benzoyl peroxide. Transmission electron microscopy (TEM) and scanning transmission electron microscopy (STEM) revealed that the micelles and their cross-linked derivatives had spherical morphologies.

Keywords: Polyimide, Poly(dimethylsiloxane), ATRP, Self-assembly 


\section{INTRODUCTION}

Polyimides (PIs) are a class of high performance rigid and glassy polymers that have attracted much attention due to their outstanding chemical, mechanical and thermal stability [1-3]. PIs have found application in the aerospace industry as composite materials, in microelectronics as inter-level insulators and as matrices for gas separation membranes $[1,2$, 4]. Most PIs are poorly processable due to their planar hetero-aromatic structures and a major effort has been devoted to the development of PIs that possess good solubility $[5,6]$. Monomers with hydrophobic trifluoromethyl groups, such as 6FDA, are often utilized in the synthesis of PIs to increase their solubility while maintaining their excellent chemical, mechanical and thermal stability [7, 8]. Poly(dimethylsiloxane) (PDMS) is a rubbery polymer that is often covalently incorporated with PI to increase its solubility and processability [9, 10]. In addition, PDMS has been utilized to impart impact resistance, low dielectric constant, low moisture uptake and thermooxidative resistance [11]. Several approaches have been reported to combine PDMS and PI; mainly through copolymerization or grafting. Covalently linked copolymers have included the grafting of PDMS along a polyimide backbone [11, 12], copolymerization of end-functionalized PDMS and PI [13-15], and end-capping of PI with linear PDMS [16]. In the past, studies involving siloxane-containing PIs have mainly focused on varying the weight fraction and the molecular weight of the siloxane segments and investigating the resulting effects on the thermal, mechanical, rheological, surface and dielectric properties of the copolymers [11-16].

Block copolymer (BCP) self-assembly has received considerable scientific attention as it represents one of the key strategies to prepare well-defined nanostructures with tunable chemical and physical properties [17, 18]. BCPs consist of several polymer blocks of different composition. Covalently linking two (or more) incompatible polymers allows the formation of ordered nano and microdomains. In the past decades, scientists have exploited 
the thermodynamic incompatibility of BCP to fabricate various functional nanomaterials [1921]. For example, ABA triblock copolymers can self-assemble to form flower type micelles in selective solvents for the middle block. Flower type micelles display interesting properties, such as low entanglement and low viscosity at high concentrations [22-24]. Based on the architecture, this type of micelle is also referred to as a 'nano-flower' (NF) [25]. Micellization of ABA triblock copolymers to form NFs have been reported for poly(2-vinyl pyridine)- $b$-polystyrene- $b$-poly(2-vinyl pyridine) $[22,26,27]$, poly(vinyl alcohol)- $b$ polystyrene- $b$-poly(vinyl alcohol) [28], poly(2-hydroxyethyl acrylate)- $b$ - poly(ethylene oxide)- $b$-poly(2-hydroxyethyl acrylate) [29], poly(methyl methacrylate)- $b$-poly(ethylene oxide)- $b$-poly(methyl methacrylate) [30-32], and polystyrene- $b$-poly(ethylene oxide)- $b$ polystyrene copolymers $[33,34]$. In these previous studies, the triblock copolymers are comprised of flexible polymer chains, however it is unclear if NF morphologies can still be formed if a copolymer with a very rigid middle block is employed.

In this article we report the synthesis of well-defined PI/PDMS triblock copolymers with very rigid PI middle blocks. The triblock copolymers were synthesized by a combination of stepand chain-growth polymerizations. The end groups and molecular weight of the PI were accurately controlled by careful manipulation of the monomer ratios. Self-assembly of the triblock copolymers was investigated in $N, N$-dimethylformamide (DMF). Surprisingly, flower-like micelles were observed and this morphology was further confirmed following cross-linking to stabilize the structure. Both the micelles and cross-linked nanoparticles were characterized to determine their size, morphology and molecular structures. The nanoparticles essentially consist of a rigid/glassy PI shell, and a soft/rubbery PDMS core. 


\section{EXPERIMENTAL}

\subsection{Materials}

2,3,5,6-Tetramethyl-1,4-phenylenediamine (TMPD, 99\%), 2-bromoisobutyryl bromide (98\%), copper(I) bromide ( $\mathrm{CuBr}, 98 \%)$, copper(II) bromide $\left(\mathrm{CuBr}_{2}, 99 \%\right)$, potassium trifluoroacetate (KTFA, 98\%), silver trifluoroacetate (AgTFA, 98\%), sodium trifluoroacetate (NaTFA, 98\%), tris[2-(dimethylamino)ethyl]amine $\left(\mathrm{Me}_{6} \mathrm{TREN}\right)$ and benzoyl peroxide $(70 \%$, remainder water) were purchased from Aldrich and used as received. Poly(dimethylsiloxane) monomethacryloxypropyl terminated $\left(M_{\mathrm{w}}=600-800 \mathrm{Da}\right)$ (PDMS-MA, 95\%, Gelest) was stirred with basic alumina (99\%, Merck) overnight and filtered prior to use. Acetone (AR), dichloromethane (DCM, AR), diethyl ether $\left(\mathrm{Et}_{2} \mathrm{O}, \mathrm{AR}\right)$, methanol $(\mathrm{MeOH}, \mathrm{AR})$ and $N, N-$ dimethylformamide (DMF, AR) were purchased from Chem-Supply and used as received. 4,4'-Hexafluoroisopropylidene (6FDA, 99\%, Alfa Aesar), trans-2-[3-(4-tert.-butyl-phenyl)2-methyl-2-propenylidene]-malononitrile (DCTB, Santa Cruz Biotechnology) and $\mathrm{N}, \mathrm{N}$ dimethylacetamide (DMAc, 99.5\%, extra dry, Acros Organics) were used as received. Tetrahydrofuran (THF, HPLC grade, RCI Labscan) was distilled from sodium benzophenone ketyl under argon. Triethylamine (TEA, 99\%, Ajax) was distilled from calcium hydride (95\%, Aldrich) under argon. Deuterated chloroform $\left(\mathrm{CDCl}_{3}, 99.9 \%\right)$ was purchased from Cambridge Isotope Laboratories, Inc. Strong carbon-coated Formvar films mounted on 300 mesh copper grids were purchased from ProSciTech. Teflon syringe filters with a pore size of $0.45 \mu \mathrm{m}$ were purchased from Labquip Technologies.

\subsection{Instrumentation}

Gel permeation chromatography (GPC) was performed on a Shimadzu liquid chromatography system fitted with a miniDAWN TREOS detector $(658 \mathrm{~nm}, 30 \mathrm{~mW})$ and a Shimadzu RID-10A refractive index detector $(633 \mathrm{~nm})$, using three Phenomenex Phenogel 
columns (500, $10^{4}, 10^{6} \AA$ porosity; $5 \mu \mathrm{m}$ bead size) maintained at $40{ }^{\circ} \mathrm{C}$. THF was used as the eluent at a flow rate of $1 \mathrm{~mL} / \mathrm{min}$. Astra software (Wyatt Technology Corp.) was used to process the data and determine molecular weight characteristics using either known $\mathrm{d} n / \mathrm{d} c$ values or based upon the assumption of $100 \%$ mass recovery of the polymer where the $\mathrm{d} n / \mathrm{d} c$ value was unknown. ${ }^{1} \mathrm{H}$ NMR spectroscopic analysis was performed on a Varian Unity Plus $500 \mathrm{MHz}$ spectrometer operating at $500 \mathrm{MHz}$, using the deuterated solvent resonance as reference. ${ }^{13} \mathrm{C}$ NMR spectroscopic analysis was performed on a Varian Unity Plus $600 \mathrm{MHz}$ spectrometer operating at $150 \mathrm{MHz}$, using the deutrated solvent resonance as reference. MALDI ToF MS was performed on a Bruker Autoflex III Mass Spectrometer operating in positive/linear mode; the analyte, matrix (DCTB) and cationisation agent (AgTFA, KTFA or NaTFA) were dissolved in THF at concentrations of 10,10 and $1 \mathrm{mg} / \mathrm{mL}$, respectively, and then mixed in a ratio of 10:1:1. 0.3 $\mu \mathrm{L}$ of this solution was then spotted onto a ground steel target plate, and the solvent was allowed to evaporate prior to analysis. FlexAnalysis (Bruker) was used to analyze the data. Dynamic light scattering (DLS) measurements were performed on a Malvern Zetasizer Nano ZS with $4.0 \mathrm{~mW}$ He-Ne laser operating at $632.8 \mathrm{~nm}$. Analysis was performed at an angle of $173^{\circ}$ and a constant temperature of $25 \pm 0.1{ }^{\circ} \mathrm{C}$. Transmission electron microscopy (TEM) images were taken using a Tecnai TF30 transmission electron microscope (FEI Co., Eindhoven, The Netherlands) operating at $200 \mathrm{kV}$. Images were acquired digitally with a Gatan US1000 2k × 2k CCD Camera (Pleasanton, CA). Elemental analysis was acquired in scanning transmission electron microscopy (STEM) mode using an EDAX X-ray detector. STEM imaging was conducted using a high angle, annular dark field detector (HAADF) to generate dark field STEM images. Spectrum line profiles were recorded across micelles using a dwell time of 5 seconds and profile size of 30 points.

\subsection{Synthesis of $\alpha, \omega$-diamino poly(6FDA-co-TMPD) P1}


6FDA (2.40 g, $5.40 \mathrm{mmol}, 5$ equiv.) and TMPD (1.09 g, $6.61 \mathrm{mmol}, 6$ equiv.) were dissolved in DMAc $(20 \mathrm{~mL})$ under argon. After stirring for $24 \mathrm{~h}$ at room temperature the mixture was refluxed for $24 \mathrm{~h}$ and then precipitated into cold $\left(-18{ }^{\circ} \mathrm{C}\right) 1: 1 \mathrm{MeOH}: \mathrm{Et}_{2} \mathrm{O}(200 \mathrm{~mL})$. The precipitate was collected by centrifugation, dried in vacuo ( 2 mbar) for $16 \mathrm{~h}$, re-dissolved in $\operatorname{DCM}(15 \mathrm{~mL})$ and re-precipitated into cold $\left(-18{ }^{\circ} \mathrm{C}\right)$ 1:1 $\mathrm{MeOH}: \mathrm{Et}_{2} \mathrm{O}(200 \mathrm{~mL})$. The precipitate was collected by centrifugation and dried in vacuo $(0.1 \mathrm{mbar})$ at $60{ }^{\circ} \mathrm{C}$ for $16 \mathrm{~h}$ to yield P1 as a faint yellow solid, $2.95 \mathrm{~g}(85 \%)$. GPC: $M_{\mathrm{n}}=5.2 \mathrm{kDa}$, PDI $=1.5$. MALDI ToF MS: $M_{\mathrm{n}}=2.8 \mathrm{kDa}, \mathrm{PDI}=1.1 .{ }^{1} \mathrm{H}$ NMR $\left(500 \mathrm{MHz}, \mathrm{CDCl}_{3}\right): \delta_{\mathrm{H}} 8.12-8.04\left(m, \mathrm{ArH}, H_{\mathrm{e}}\right)$, $8.02-7.91\left(m, \mathrm{ArH}, H_{\mathrm{d}} \& H_{\mathrm{c}}\right), 2.14\left(\mathrm{br} s, \mathrm{CH}_{3}, H_{\mathrm{a}}\right), 2.06$ (br s, ArH, $H_{\mathrm{b}}$ end-group) ppm (Figure S1). ${ }^{13} \mathrm{C}$ NMR $\left(150 \mathrm{MHz}, \mathrm{CDCl}_{3}\right): \delta_{\mathrm{C}} 13.7,15.4,15.7,118.7,119.6,122.4,124.0$, $124.2-124.4(m), 125.4,125.5,130.8,132.2,132.4,132.5,132.7,132.8,132.9,134.0$ 135.7, 136.0, 138.9, 139.2, 139.3, 144.2, 165.7 - $165.8(\mathrm{~m}), 166.0,166.8,167.1 \mathrm{ppm}$ (Figure S2).

2.4 Synthesis of $\alpha, \omega$-dibromo poly(functionalized 6FDA-co-TMPD) macroinitiator P2 Poly(6FDA-co-TMPD) P1 (2.80 g, $0.48 \mathrm{mmol}, 1$ equiv.) was dissolved in THF (15 mL) under argon. TEA (0.75 mL, $5.38 \mathrm{mmol}, 10$ equiv.) was added, followed by the dropwise addition of 2-bromoisobutyrl bromide (1.24 g, $5.38 \mathrm{mmol}, 10$ equiv.). The mixture was stirred at room temperature for $4 \mathrm{~h}$ and precipitated into cold $\left(-18{ }^{\circ} \mathrm{C}\right)$ methanol thrice $(3 \times$ $150 \mathrm{~mL})$. The precipitate was isolated via filtration and dried in vacuo $(0.1 \mathrm{mbar})$ at $60{ }^{\circ} \mathrm{C}$ for $16 \mathrm{~h}$ to yield P2 as a white solid, $2.93 \mathrm{~g}(89 \%)$. GPC: $M_{\mathrm{n}}=5.9 \mathrm{kDa}, \mathrm{PDI}=1.5$. MALDI ToF MS: $M_{\mathrm{n}}=3.1 \mathrm{kDa}, \mathrm{PDI}=1.1 .{ }^{1} \mathrm{H}$ NMR $\left(500 \mathrm{MHz}, \mathrm{CDCl}_{3}\right): \delta_{\mathrm{H}} 8.11-8.05\left(m, \mathrm{ArH}, H_{\mathrm{e}}\right)$, $8.02-7.93\left(m, \mathrm{ArH}, H_{\mathrm{d}} \& H_{\mathrm{c}}\right), 2.21\left(b r s, \mathrm{CH}_{3}, H_{\mathrm{f}}\right.$ end-group), $2.14\left(b r s, \mathrm{CH}_{3}, H_{\mathrm{a}}\right), 2.11(b r$ $s, \mathrm{CH}_{3}, H_{\mathrm{b}}$ end-group), 2.09 ( $b r s, \mathrm{CH}_{3}, H_{\mathrm{c}}$ end-group) ppm (Figure S3). ${ }^{13} \mathrm{C}$ NMR (150 $\left.\mathrm{MHz}, \mathrm{CDCl}_{3}\right): \delta_{\mathrm{C}} 15.3,15.4,15.5,15.7,15.8,15.9,32.6,32.7,120.5,122.4,124.2-124.4$ 
$(m), 125.4,125.5,128.8,130.8,132.4,132.8,132.9,133.4,134.0,134.8,135.9-136.1(m)$, 139.2, $165.7-165.8(\mathrm{~m}), 166.0,170.2 \mathrm{ppm}$ (Figure S4).

\subsection{Synthesis of polyimide/poly(dimethylsiloxane) copolymers $\boldsymbol{P 3}$}

Poly(6FDA-co-TMPD) macroinitiator P2 (0.25 g, $42.4 \mu$ mol, 1 equiv.), $\mathrm{Me}_{6}$ TREN (22.7 $\mu \mathrm{L}$, $84.8 \mu$ mol, 2 equiv.) and PDMS-MA (5-15 equiv., refer to Table 2 ) were dissolved in THF in a Schlenk tube (oven-dried at $110{ }^{\circ} \mathrm{C}$ for $24 \mathrm{~h}$ ) to afford a monomer concentration of $0.2 \mathrm{M}$. An aliquot $(0.2 \mathrm{~mL})$ was taken $\left(t_{0}\right)$ to monitor monomer conversion. The mixture was then subjected to three freeze-pump-thaw cycles and the Schlenk tube was then immersed again in liquid $\mathrm{N}_{2}$. Once the solution was frozen $\mathrm{CuBr}(12.2 \mathrm{mg}, 84.8 \mu \mathrm{mol}, 2$ equiv.) was added and another three freeze-pump-thaw cycles were performed. The Schlenk tube was allowed to equilibrate at room temperature for $5 \mathrm{~min}$ with stirring to ensure homogeneity and then heated at $50{ }^{\circ} \mathrm{C}$ for $24 \mathrm{~h}$. After cooling to room temperature an aliquot $(0.2 \mathrm{~mL})$ was taken $\left(t_{24}\right)$ to determine monomer conversion. The reaction mixture was then diluted with THF (3 $\mathrm{mL}$ ) and passed through a plug of basic alumina to remove the copper catalyst. The filtrate was concentrated in vacuo and then dried in vacuo $(0.1 \mathrm{mbar})$ at $120{ }^{\circ} \mathrm{C}$ for $16 \mathrm{~h}$ to yield P31, P3-2 and P3-3 as pale yellow tacky solids (P3-1: 94\%; P3-2: 92\%; P3-3: 87\%). The polymer composition was varied by changing the monomer:initiator ratio (Table 2). ${ }^{1} \mathrm{H}$ NMR $\left(500 \mathrm{MHz}, \mathrm{CDCl}_{3}\right): \delta_{\mathrm{H}} 8.12-7.90\left(m, \mathrm{ArH}, H_{\mathrm{a}}\right), 3.87\left(\right.$ br s $\left., \mathrm{CH}_{2} \mathrm{O}, H_{\mathrm{e}}\right), 2.15\left(b r s, \mathrm{ArCH}_{3}\right.$, $\left.H_{\mathrm{b}}\right), 1.78\left(b r s, \mathrm{CH}_{2} \mathrm{C}, H_{\mathrm{c}}\right), 1.67-1.49\left(m, \mathrm{CH}_{2}, H_{\mathrm{f}}\right), 1.38-1.24\left(m, \mathrm{CH}_{2}, H_{\mathrm{i}}\right), 1.15-0.77$ $\left(m, \mathrm{CH}_{3}, H_{\mathrm{d}}, H_{\mathrm{j}}\right), 0.60-0.45\left(m, \mathrm{SiCH}_{2}, H_{\mathrm{g}}\right), 0.30--0.1\left(\mathrm{~m}, \mathrm{SiCH}_{3}, H_{\mathrm{h}}\right) \mathrm{ppm}$.

\subsection{Self-assembly of polyimide/poly(dimethylsiloxane) copolymers}

THF and DMF for self assembly studies were pre-filtered through $0.45 \mu \mathrm{m}$ PTFE filters (Labquip Technologies). Copolymers were dissolved in THF $(30 \mathrm{mg} / \mathrm{mL})$ and then treated dropwise with DMF to effect dissolution $(1.0 \mathrm{mg} / \mathrm{mL})$. Samples were left overnight prior to 
analysis. DLS and TEM were used to analyze the structure and morphology of the copolymers.

\subsection{Cross-linking of polyimide/poly(dimethylsiloxane) copolymers}

5.0 $\mathrm{mg}$ of P3-1 and $0.5 \mathrm{~g}$ of benzoyl peroxide were dissolved in THF (P3.1: $30 \mathrm{mg} / \mathrm{mL}$ ) and then treated dropwise with DMF to effect dissolution (P3-1: $1.0 \mathrm{mg} / \mathrm{mL})$. The sample was analyzed by DLS and then bubbled with argon for an hour. An aliquot (1.5 mL) was quickly added to a $4 \mathrm{~mL}$ vial (backpurged with argon) by removing and recapping the plastic cap. The solution was stirred at $90{ }^{\circ} \mathrm{C}$ for 7 hours and the solvent was removed in vacuo $(0.1$ mbar) to yield a faint yellow solid. The dried product was then dissolved in pre-filtered THF $(1.5 \mathrm{~mL})$ for post cross-linking DLS analysis. An equivalent amount of polymer and benzoyl peroxide were also used to cross-link P3-2 and P3-3.

\subsection{Imaging of uncrosslinked polyimide/poly(dimethylsiloxane) copolymers}

The TEM and STEM samples were prepared by dissolving P3-2 in THF (30 mg/mL), treated dropwise with DMF to effect dissolution $(0.5 \mathrm{mg} / \mathrm{mL})$, drop-coated onto the copper TEM grids $(5 \mu \mathrm{L})$, blotted and negatively stained by uranyl acetate aqueous solution (2 wt $\%)$ before imaging was conducted.

\subsection{Imaging of cross-linked polyimide/poly(dimethylsiloxane) copolymers}

The TEM and STEM samples were prepared by drop-coating cross-linked P3-2 in THF (0.1 $\mathrm{mg} / \mathrm{mL})$ onto the copper TEM grids $(5 \mu \mathrm{L})$, blotted and negatively stained by uranyl acetate aqueous solution ( $2 \mathrm{wt} \%$ ) before imaging was conducted. 


\section{RESULTS AND DISCUSSION}

A combination of step- and chain-growth polymerizations was employed to prepare welldefined brush triblock copolymers (Scheme 1). Initially, 'glassy' fluorinated polyimide, poly(6FDA-co-TMPD) (P1), with a very high proportion of amino end-groups was synthesized via step-growth polymerization and subsequently functionalized to afford the $\alpha, \omega$-dibromo terminated difunctional macroinitiator $\mathbf{P 2}$, suitable for atom transfer radical polymerization (ATRP). The well-defined diamino terminated polyimide and its functionalized derivative were characterized via gel permeation chromatography (GPC), nuclear magnetic resonance (NMR) spectroscopic analysis and matrix-assisted laser desorption/ionization time-of-flight mass spectroscopy (MALDI ToF MS). The poly(6FDAco-TMPD) macroinitiator P2 was subsequently chain extended with varying amounts of PDMS-MA macromonomer to afford a series of novel block copolymers containing glassy and rubbery segments, with constant and variable degrees of polymerisation (DP), respectively.

\subsection{Synthesis of $\alpha, \omega$-diamino poly(6FDA-co-TMPD) P1}

Fluorinated polyimide, poly(6FDA-co-TMPD) P1, with amino end-groups was synthesized via a standard two-step step-growth polymerization involving anhydride ring-opening and thermal cyclodehydration (Scheme 1). An exact molar ratio of 6FDA and TMPD (5:6) was utilized to control the DP and ensure a very high proportion of amino end-groups. In the presence of nucleophiles such as water, the anhydride groups of 6FDA are readily hydrolyzed to form ortho dicarboxylic groups, which are unreactive towards polymerization, thus the use of anhydrous solvents and inert environments are crucial to obtain well-defined polymers [1]. In this study, thermal imidization (also known as cyclodehydration) at $180{ }^{\circ} \mathrm{C}$ was conducted, since the commonly employed chemical imidization in the presence of drying agents (e.g., acetic anhydride) and base catalyst would have resulted in undesirable acetylation of the 
terminal amine groups [34]. Subsequently, the $\alpha, \omega$-diamino poly(6FDA-co-TMPD) P1 was isolated via precipitation. ${ }^{1} \mathrm{H}$ NMR spectroscopic analysis confirmed that complete imidization was achieved as indicated by the absence of resonances corresponding to carboxylic protons (typically in the $\delta_{\mathrm{H}}$ 10.5-13 ppm region; Figure S1), and revealed the presence of aromatic methyl protons adjacent to the amine end-groups (Figure 1a). Integration of the characteristic end-group and backbone resonances provided a numberaverage molecular weight $\left(M_{\mathrm{n}}\right)$ of $3.8 \mathrm{kDa}$, which is very similar to the theoretical $M_{\mathrm{n}}(3.2$ $\mathrm{kDa})$ based upon the monomer ratio employed. In comparison, the $M_{\mathrm{n}}(5.2 \mathrm{kDa})$ determined by GPC based upon the assumption of 100\% mass recovery, was slightly higher (Table 1). 


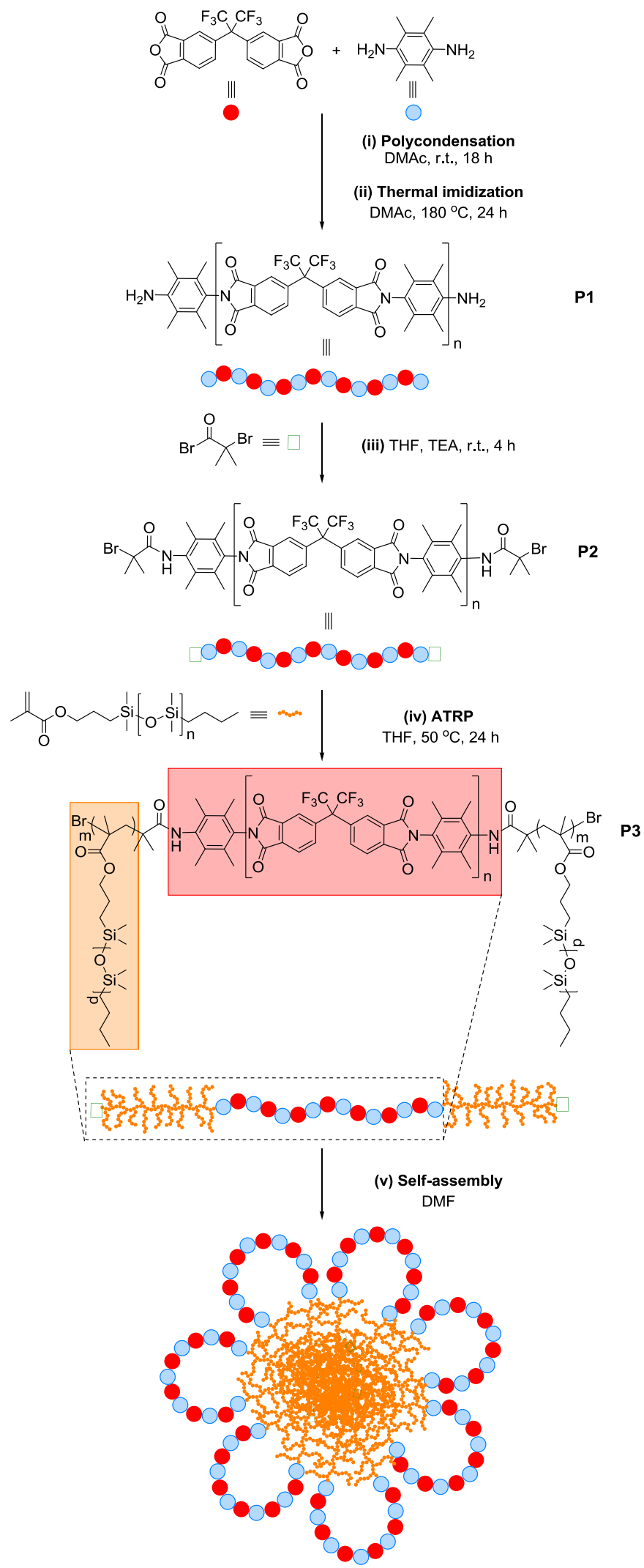

Scheme 1. Synthetic outline for the preparation of polyimide/poly(dimethylsiloxane) copolymers and their self-assemblies. 
MALDI ToF MS was utilized to determine the molecular weight and end-group composition of the polyimide P1. The mass spectrum of polyimide $\mathbf{P 1}$ obtained using silver trifluoroacetate (AgTFA) as the cationisation agent revealed several series of peaks separated by $c$ a. $573 \mathrm{~m} / \mathrm{z}$, which corresponds to the repeat unit of poly(6FDA-co-TMPD) (Figure 2a). The mass values of the major series of peaks were found to correlate well with the expected masses of the $\mathrm{Ag}^{+}$salt of $\alpha, \omega$-diamino poly(6FDA-co-TMPD). Importantly, no series of peaks corresponding to mono- or di-anhydride terminated poly(6FDA-co-TMPD) were observed. A very minor, unidentified series $(<1.5 \%)$ was attributed to fragmentation of the polyimide during the MS ionization process. The very high extent of amino end-groups observed in the mass spectrum supports the NMR spectroscopy results, and is attributed to the excess of TMPD used in the polymerisation. To ensure that the observed mass series correlates to the expected $\mathrm{Ag}^{+}$salt, other cations (e.g., $\mathrm{Na}^{+}$and $\mathrm{K}^{+}$) were also employed in the analysis and resulted in characteristic shifts in the polyimide mass series corresponding to those salts (Figure S5). Determination of the $M_{\mathrm{n}}$ via MALDI ToF MS provided a value of 2.8 $\mathrm{kDa}$, which is slightly lower than that calculated from NMR spectroscopy (Table 1). The observed discrepancy most likely results from preferential ionization of low molecular weight species during MS analysis [35].

\subsection{Synthesis of $\alpha, \omega$-dibromo poly(6FDA-co-TMPD) macroinitiator P2}

Functionalization of polyimide P1 with initiating moieties was achieved through reaction with 2-bromoisobutyryl bromide to afford the $\alpha, \omega$-dibromo poly(6FDA-co-TMPD) macroinitiator P2 in quantitative yield (Scheme 1) [36]. GPC analysis of macroinitiator P2 revealed an increase in $M_{n}$ from $5.2 \mathrm{kDa}(\mathbf{P 1})$ to $5.9 \mathrm{kDa}(\mathbf{P 2})$ (Table 1). ${ }^{1} \mathrm{H} \mathrm{NMR}$ spectroscopic analysis of $\mathbf{P 2}$ revealed a new resonance at $\delta_{H} 2.2 \mathrm{ppm}$ (Figure 1b) corresponding to the methyl groups of the bromoisobutyramide end-groups, which was 
accompanied by a down-field shift of the adjacent aromatic methyl protons from $\delta_{H} 2.09$ (Figure 1a) to $2.11 \mathrm{ppm}$ (Figure 1b).

(a)
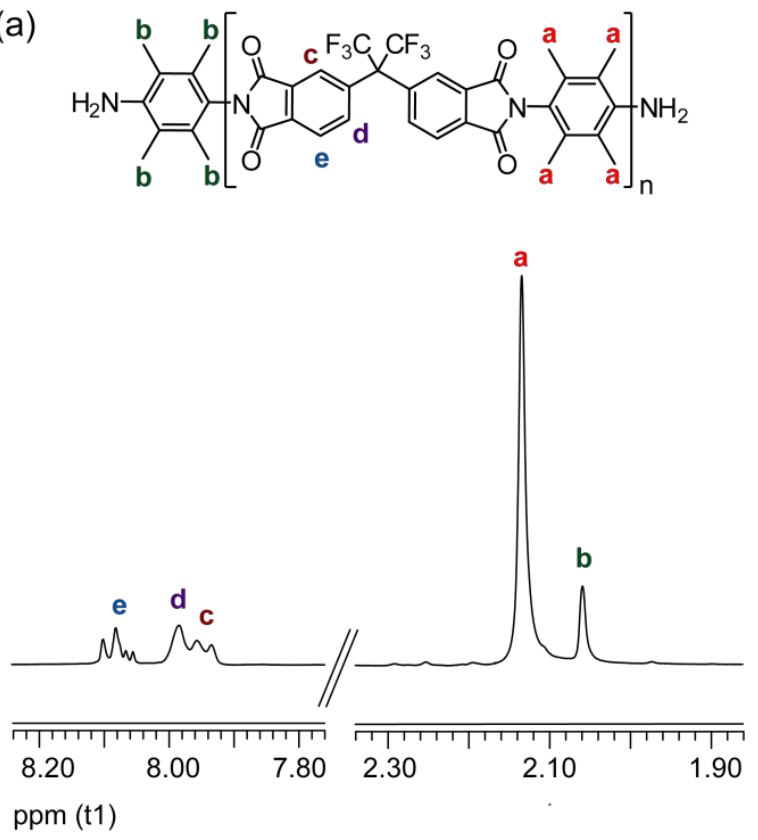

(b)
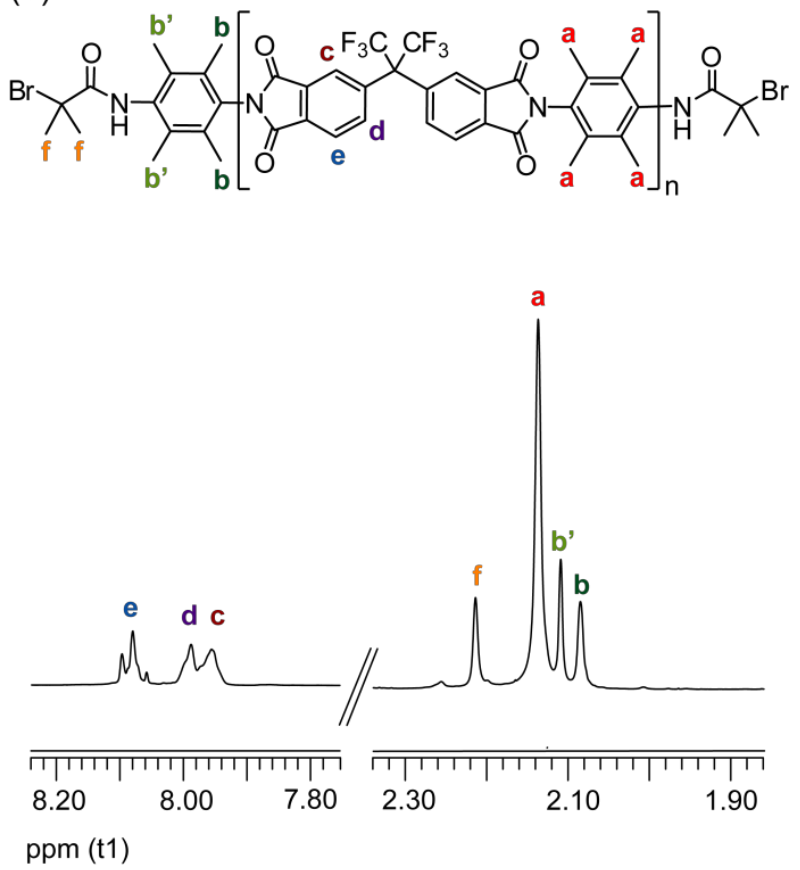

Figure 1. ${ }^{1} \mathrm{H}$ NMR spectra $\left(\mathrm{CDCl}_{3}\right)$ of poly(6FDA-co-TMPD) (a) P1 and (b) $\mathbf{P 2}$.

As for P1, MALDI ToF MS was used to characterize macroinitiator $\mathbf{P 2}$ using identical conditions (e.g., AgTFA) and revealed a series of peaks separated by $c a .573 \mathrm{~m} / \mathrm{z}$ (Figure 2b). In theory, the addition of two bromoisobutyramide end-groups should result in a $298 \mathrm{~m} / \mathrm{z}$ 
shift in the mass series to higher values relative to the diamino polyimide P1 mass series (Figure 2a). However, examination of the mass values revealed a shift of $c a .136 \mathrm{~m} / \mathrm{z}$ instead of the expected value of $298 \mathrm{~m} / \mathrm{z}$, which is attributed to fragmentation of the bromine atoms during the MS ionization process. Taking this into account, the observed mass values were found to correlate well with the desired dibromo polyimide P2. The utilization of other cationisation agents (e.g., $\mathrm{Na}^{+}$and $\mathrm{K}^{+}$) resulted in characteristic shifts in the polyimide mass series corresponding to those salts (Figure S6), although fragmentation of the bromine atoms was observed in all cases.

Table 1. Molecular weight characterization of polyimides $\mathbf{P 1}$ and $\mathbf{P 2}$.

\begin{tabular}{cccccc}
\hline Polymer & $M_{\mathrm{n}}{ }^{\text {theor }}(\mathrm{kDa})^{a}$ & $M_{\mathrm{n}}{ }^{N M R}(\mathrm{kDa})^{b}$ & $\begin{array}{c}M_{n}{ }^{\text {MALDIToF }} \\
(\mathrm{kDa})^{c}\end{array}$ & $M_{\mathrm{n}}{ }^{G P C}(\mathrm{kDa})^{d}$ & $\mathrm{PDI}^{d}$ \\
\hline \hline P1 & 3.2 & 3.8 & 2.8 & 5.2 & 1.5 \\
P2 & 3.5 & 4.1 & 3.1 & 5.9 & 1.5 \\
\hline
\end{tabular}

${ }^{a}$ Number-average molecular weight based upon the precise monomer ratio of the diamine (TMPD) to dianhydride (6FDA) employed. ${ }^{b}$ Number-average molecular weight calculated from ${ }^{1} \mathrm{H}$ NMR spectroscopic analysis. ${ }^{c}$ Number-average molecular weight determined by MALDI ToF MS. Number-average molecular weight and polydispersity index (PDI) measured by GPC based upon the assumption of $100 \%$ mass recovery. 

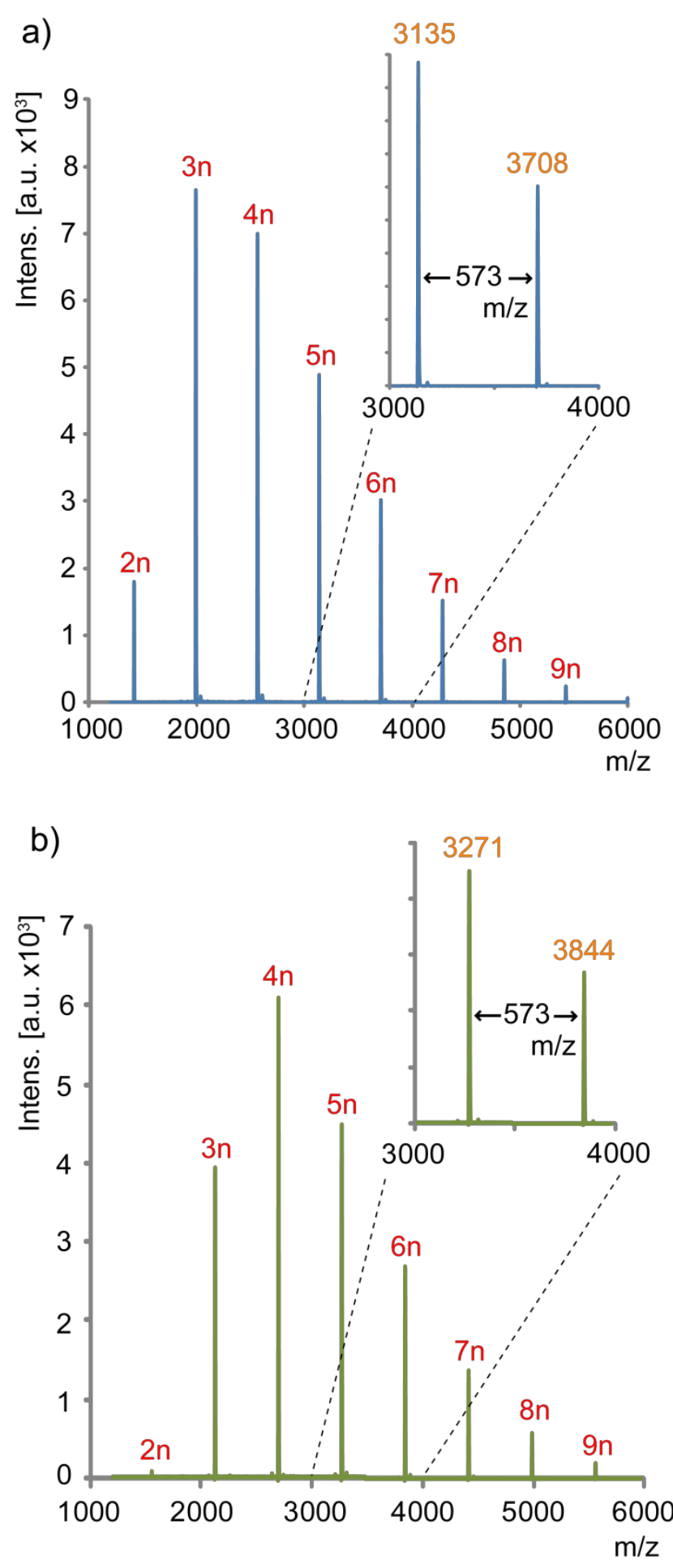

Figure 2. MALDI ToF mass spectra of (a) diamino poly(6FDA-co-TMPD) P1 and (b) dibromo macroinitiator P2 recorded in linear/positive mode using DCTB and AgTFA as the matrix and cationisation agent, respectively. The numbers on the peaks denote the number of repeat units $(\mathrm{n}, 573$ $\mathrm{m} / \mathrm{z})$ 


\subsection{Synthesis of polyimide/poly(dimethylsiloxane) brush copolymers}

Triblock copolymers were synthesized via ATRP using $\mathrm{Cu}(\mathrm{I}) / \mathrm{Me}_{6} \mathrm{TREN}$ as the catalyst/ligand system (Scheme 1) and $\alpha, \omega$-dibromo poly(6FDA-co-TMPD) P2 as the macroinitiator and PDMS-MA as the macromonomer. $\mathrm{Me}_{6}$ TREN was chosen as the ligand as previous studies indicated that the use of other ligands with low rates of activation $\left(k_{\mathrm{a}}\right)$, such as PMDETA or bipyridine, result in low conversions [37]. ATRP of PDMS-MA macromonomer initiated with $\mathbf{P 2}$ at various monomer to initiator ratios (Table 2) yielded the copolymers (P3-1 to P3-3) as pale yellow tacky solids. ${ }^{1} \mathrm{H}$ NMR spectroscopic analysis revealed high PDMS-MA conversions, up to $94 \%$, and $M_{\mathrm{n}}$ values ranging from 10.1 to 23.3 $\mathrm{kDa}$ (Table 2). GPC analysis of P3-1 to P3-3 provided $M_{\mathrm{n}}$ values in good agreement to those calculated by ${ }^{1} \mathrm{H}$ NMR spectroscopic analysis (Table 2).

Table 2. Synthesis and characterization of polyimide/poly(dimethylsiloxane) copolymers.

\begin{tabular}{|c|c|c|c|c|c|c|}
\hline Polymer & $\begin{array}{c}\text { Molar ratio } \\
{\left[\text { PDMSMA]:[P2]:[CuBr]:[} \mathrm{Me}_{6}{ }^{\mathrm{TREN}}\right]}\end{array}$ & $\begin{array}{c}\text { Conversion }^{a} \\
(\%)\end{array}$ & $\begin{array}{l}M_{\mathrm{n}}^{G P C} \\
(\mathrm{kDa})^{b}\end{array}$ & $\begin{array}{l}M_{\mathrm{n}}^{N M R} \\
(\mathrm{kDa})^{c}\end{array}$ & $\mathrm{PDI}^{b}$ & $\begin{array}{l}\text { Yield } \\
(\%)^{d}\end{array}$ \\
\hline P3-1 & $5: 1: 2: 2$ & 88 & 9.7 & 10.1 & 1.9 & 94 \\
\hline P3-2 & $10: 1: 2: 2$ & 92 & 16.8 & 16.7 & 1.9 & 92 \\
\hline P3-3 & $15: 1: 2: 2$ & 94 & 22.8 & 23.3 & 1.9 & 87 \\
\hline
\end{tabular}

${ }^{a}$ PDMS-MA macromonomer conversion was calculated from ${ }^{1} \mathrm{H}$ NMR spectroscopic analysis. ${ }^{b}$ Number-average molecular weight and polydispersity measured by GPC based upon the assumption of $100 \%$ mass recovery. ${ }^{c}$ Number-average molecular weight of the copolymers calculated from ${ }^{1} \mathrm{H}$ NMR spectroscopic analysis. ${ }^{d}$ Isolated yield.

Closer examination of the GPC refractive index chromatograms of copolymers P3-1 to P3-3 revealed a shoulder at ca. $29 \mathrm{~min}$, which corresponds to unreacted PDMS-MA (Figure 3). Even though multiple precipitations were conducted, the association of unreacted PDMS-MA with the high density brushes made it difficult to completely remove. 


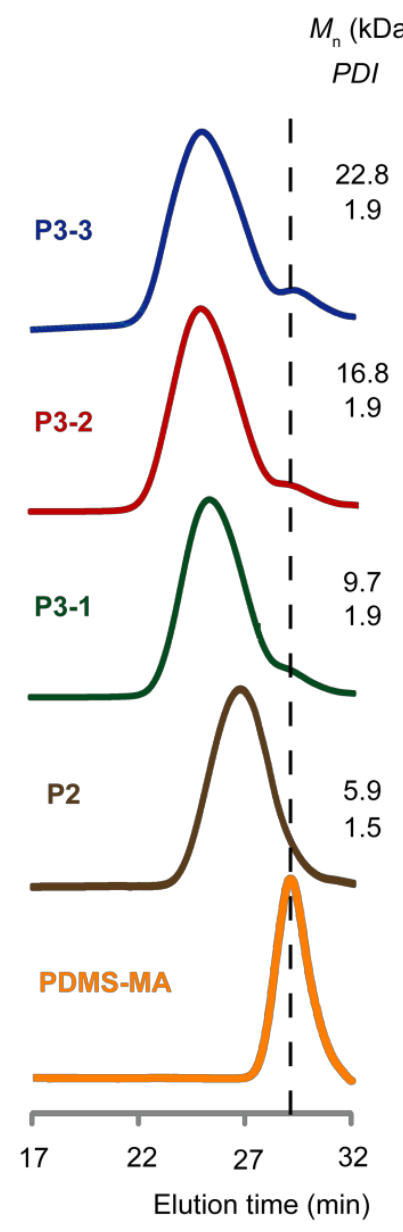

Figure 3. GPC differential refractive index (DRI) chromatograms of polyimide/poly(dimethylsiloxane) copolymers P3-1 to P3-3 and their precursors, macroinitiator P2 and PDMS-MA macromonomer. The molecular weight of PDMS-MA could not be determined via GPC as a result of weak light scattering signals, however, the manufacturer specifies a molecular weight of 600-800 Da.

${ }^{1} \mathrm{H}$ NMR spectroscopic analysis of the copolymers P3-1 to P3-3 (Figure 4), revealed characteristic methylene and methyl proton resonances $\left(\mathrm{ca} . \delta_{\mathrm{H}} 1.8\right.$ and $\left.1.0 \mathrm{ppm}\right)$ associated with the methacrylate polymer backbone, thus comfirming the synthesis of the polyimide/poly(dimethylsiloxane) copolymers. The integral ratios of the polyimide aromatic protons $\left(\mathrm{ca} . \delta_{\mathrm{H}} 8.0 \mathrm{ppm}\right)$ and the methylene protons $\left(\delta_{\mathrm{H}} 3.9 \mathrm{ppm}\right)$ adjacent to the ester groups in the PDMS-MA block were used to calculate the $M_{\mathrm{n}}$ values (Table 2). 


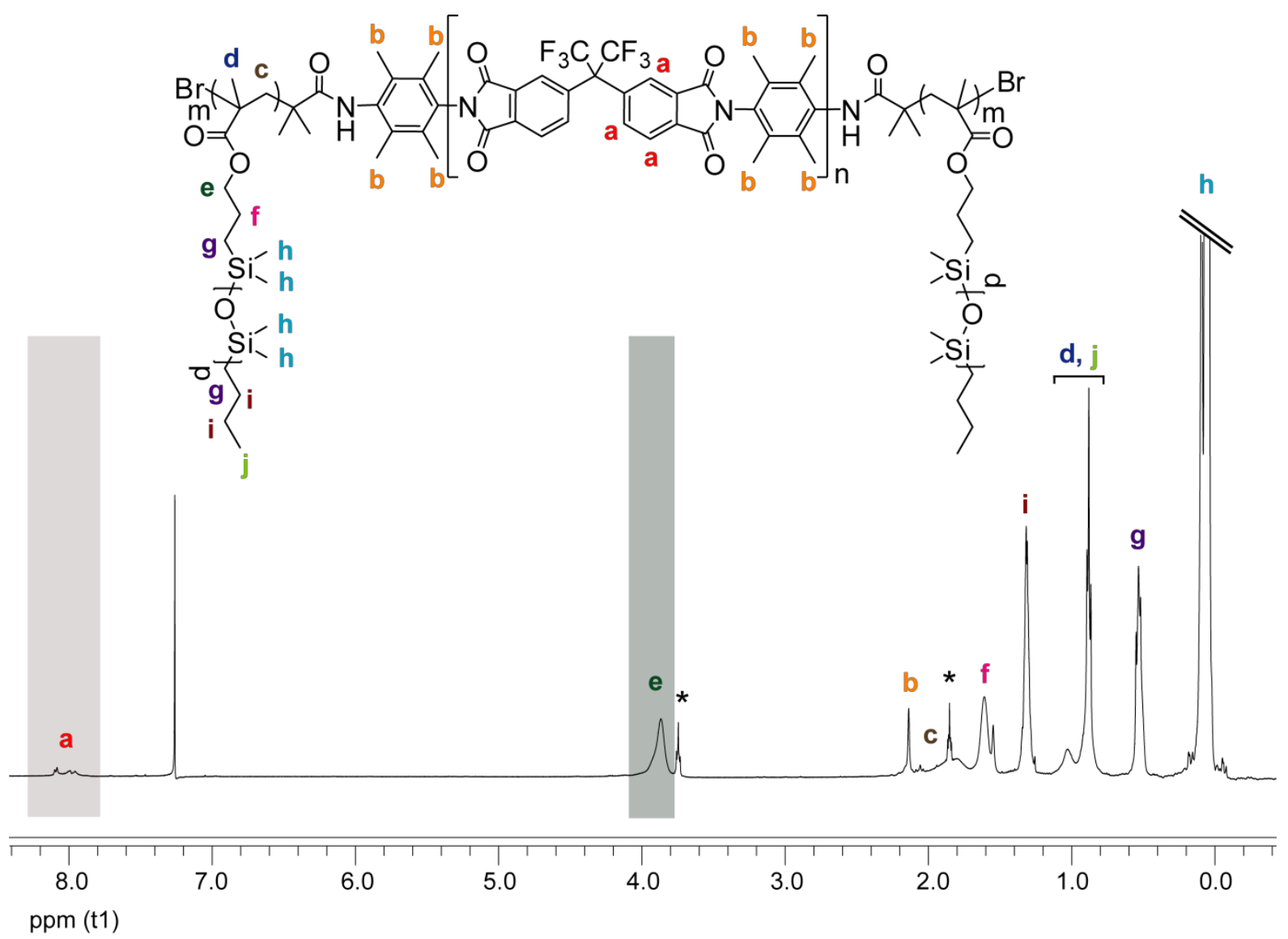

Figure 4. ${ }^{1} \mathrm{H}$ NMR spectrum $\left(\mathrm{CDCl}_{3}\right)$ of fractionated polyimide/poly(dimethylsiloxane) copolymer P3-3. The asterisk denotes residual THF solvent. 


\subsection{Self-assembly of the polyimidelpoly(dimethylsiloxane) copolymers}

Self-assembly of the triblock copolymers in DMF afforded stable micelles with soft PDMS cores surrounded by a glassy PI shell. The micellular structure was stabilized via radical induced covalent cross-linking, which was achieved via hydrogen abstraction through the thermal degradation of benzoyl peroxide. The intensity-average hydrodynamic diameters $\left(\mathrm{d}_{\mathrm{H}}\right)$ of the polyimide/poly(dimethylsiloxane) copolymers after self-assembly in DMF were characterized via DLS (Figure 5) and found to range from 87 to $109 \mathrm{~nm}$ (Table 3). Correlation function plots revealed smooth profiles for all samples, implying little or no aggregation in the measured samples (Figure 5a).

a)

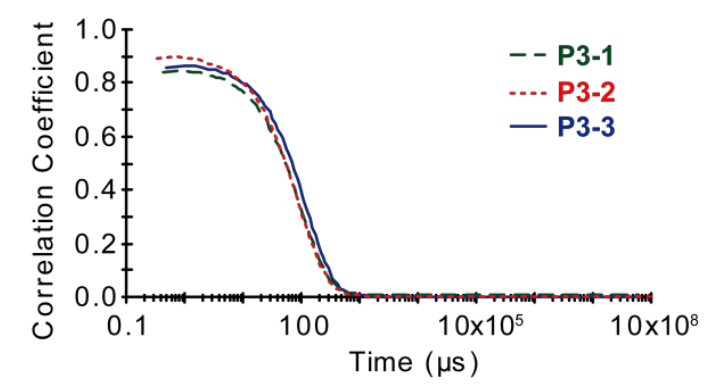

b)

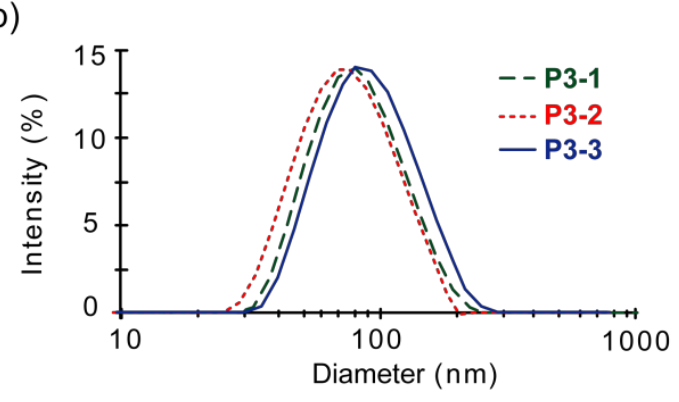

Figure 5. (a) Correlation function and (b) intensity-average hydrodynamic radius distributions of polyimide/poly(dimethylsiloxane) copolymer self-assemblies.

The $d_{H}$ of the P3-1 micelle is relatively large when compared to the P3-2 micelle (Table 3), which is believed to be a function of the PDMS-MA content. Based upon NMR spectroscopic analysis the weight percentage of the poly(PDMS-MA) blocks is smaller for P3-1 than that of P3-2 (Table 3), which may result in weaker interactions between the PDMS segments for P3-1. The rigid poly(6FDA-co-TMPD) shell combined with weaker PDMS interactions in 
the core results in a slightly larger $\mathrm{d}_{\mathrm{H}}$ for the P3-1 micelles when compared to P3-2 micelles. The increase in PDMS-MA content also results in more uniform micelles as the polydispersity index (PDI) decreased from 0.20 to 0.17 (Table 3). A further increase in PDMS-MA content, from P3-2 (65 wt $\%$ ) to P3-3 (74 wt $\%$ ), did not result in a further decrease in $d_{H}$ as stable micelles with longer PDMS-MA blocks were formed. Hence, the increase in $\mathrm{d}_{\mathrm{H}}$ observed in going from P3-2 $(87 \mathrm{~nm})$ to P3-3 $(109 \mathrm{~nm})$ micelles (Table 3) is attributed to an increase in PDMS in the core.

Table 3. Hydrodynamic radius of polyimide/poly(dimethylsiloxane) copolymer self-assemblies.

\begin{tabular}{|c|c|c|c|}
\hline \multirow{2}{*}{ Polymer } & \multicolumn{2}{|c|}{ Crude } & \multirow{2}{*}{$\mathbf{w t}^{2} \mathbf{P D M S}^{a}$} \\
\hline & $\mathbf{d}_{\mathbf{H}}(\mathbf{n m})$ & PDI & \\
\hline P3-1 & 96 & 0.20 & 39 \\
\hline P3-2 & 87 & 0.17 & 65 \\
\hline P3-3 & 109 & 0.16 & 74 \\
\hline
\end{tabular}

${ }^{a} \mathrm{wt} \%$ PDMS calculated from number-average molecular weight measured by GPC based upon the assumption of $100 \%$ mass recovery. 


\subsection{Cross-linking of the polyimide/poly(dimethylsiloxane) copolymers}

Cross-linking of the flower-like micelles was conducted to covalently stabilize the micelle structure and form soft-core glassy-shell nanoparticles. In general, there are many possible approaches to prepare cross-linked polysiloxanes, these include (i) the use of multi-functional siloxane comonomers, (ii) the incorporation of a photo or thermal radical initiators that induce radical cross-linking or (iii) exposure to high energy irradiation (e.g., gamma-rays) to generate radicals $[38,39]$. For simplicity, benzoyl peroxide (BP), a thermal radical initiator, was used to cross-link both the core and shell through radical dimerisation reactions, for which several mechanisms have been proposed for PDMS-based systems (Figure 7) [40].

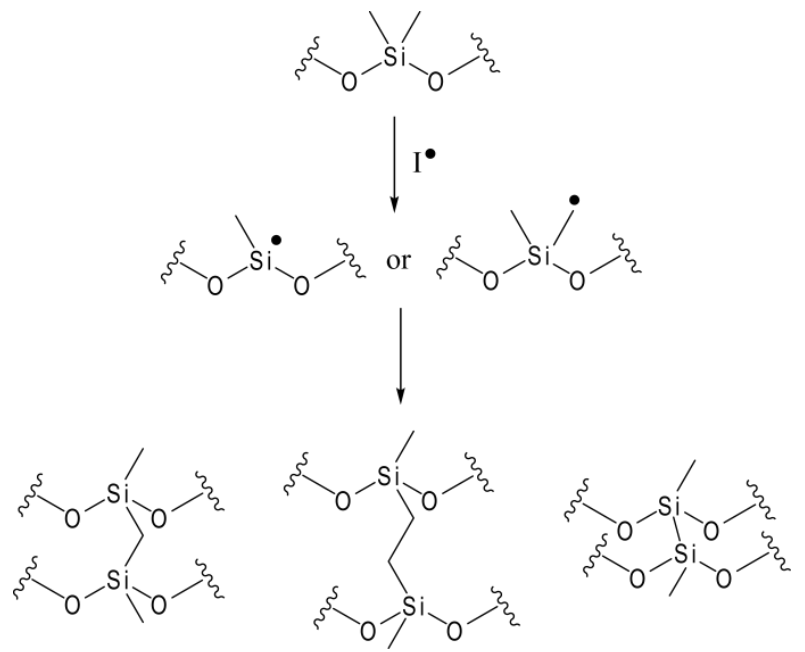

Figure 6. The mechanism of radical induced cross-linking of PDMS proposed by Charlesby [41].

Both the triblock copolymer and BP were initially dissolved together in a good solvent (THF) for both the PDMS and polyimide segments before the addition of a PI selective solvent (DMF) to promote the incorporation of BP into the core of the self-assemblies. After dissolution in DMF the samples were analyzed via DLS (Table 4), which revealed an increase in the micelle size upon the addition of BP, thus inferring its incorporation into the core of the micelles or reorganization of micelles to form larger aggregates. The increase in 
size was accompanied by an increase in PDI (Table 4). Before the cross-linking process, samples were bubbled with argon for an hour to minimize the presence of oxygen, which would compete with the desired radical cross-linking mechanism. Previous studies have indicated that polymer radicals, which are generated through hydrogen abstraction from the degradation of thermal initiators, can be converted into their oxidative derivatives in the presence of oxygen and are thus not able to participate in the cross-linking process [42]. These derivatives were identified as carboxylic acid and two peroxides of the type Si-O-OC[43].

Table 4. Hydrodynamic radius of the copolymer self-assemblies before and after crosslinking.

\begin{tabular}{ccccccc}
\hline \multirow{2}{*}{ Polymer } & \multicolumn{2}{c}{ Original } & \multicolumn{2}{c}{ Addition of BP } & \multicolumn{2}{c}{ Cross-linked } \\
& $\mathbf{d}_{\mathbf{H}}(\mathbf{n m})$ & PDI & $\mathbf{d}_{\mathbf{H}}(\mathbf{n m})$ & PDI & $\mathbf{d}_{\mathbf{H}}(\mathbf{n m})$ & PDI \\
\hline \hline P3-1 & 96 & 0.20 & 176 & 0.24 & 137 & 0.21 \\
P3-2 & 87 & 0.17 & 146 & 0.22 & 125 & 0.18 \\
P3-3 & 109 & 0.16 & 257 & 0.27 & 137 & 0.19 \\
\hline
\end{tabular}

The samples were heated at $90{ }^{\circ} \mathrm{C}$ for 7 hours for the cross-linking process. After the removal of the solvent, samples were diluted with THF to verify the extent of cross-linking; THF is a good solvent for both blocks. From DLS analysis a single peak was detected, which implied that all of the self-assembled copolymers (P3-1 to P3-3) had been fully cross-linked. Additionally, correlation function plots revealed smooth profiles, verifying no aggregation in the measured samples. 
a)

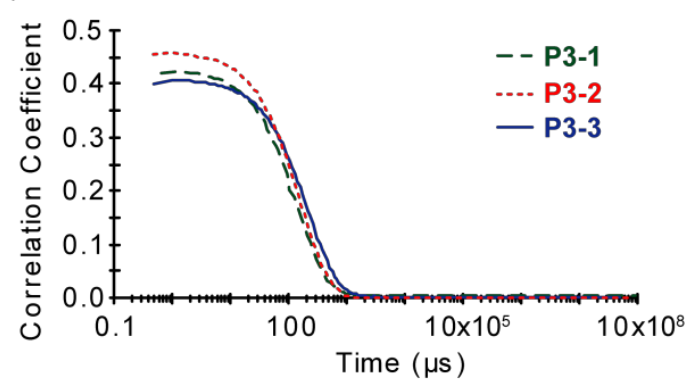

b)

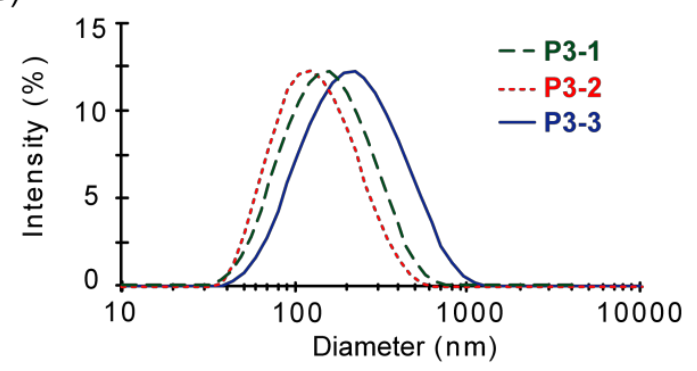

c)

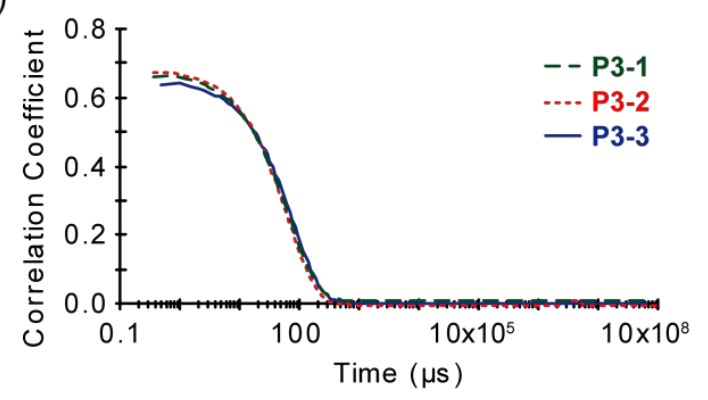

d)

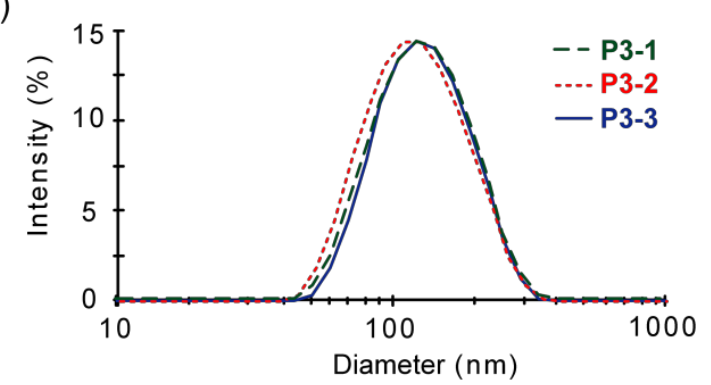

Figure 7. (a, c) Correlation function and (b, d) intensity-average hydrodynamic radius distributions of polyimide/poly(dimethylsiloxane) copolymer self-assemblies upon the addition of benzoyl peroxide and post cross-linking.

\subsection{Imaging of the polyimide/poly(dimethylsiloxane) copolymers}

Representative TEM images of the polyimide/poly(dimethylsiloxane) copolymer micelles are shown in Figure 8. Copolymer P3-2 displayed micelles with a spherical morphology and diameters of 70 to $100 \mathrm{~nm}$ (Figure 8a), which is in agreement with the DLS results $\left(\mathrm{d}_{\mathrm{H}}=87\right.$ $\mathrm{nm}, \mathrm{PDI}=0.17)($ Table 3). Based on the obtained image (Figure 8c), the corresponding cross-linked copolymers have a more irregular shape, which is most likely due to the uncontrolled nature of the cross-linking process. The image also revealed that the size of cross-linked micelles ranges from 80 to $150 \mathrm{~nm}$, which is again in agreement with the result obtained from the DLS analysis $\left(d_{H}=125 \mathrm{~nm}\right.$, PDI $\left.=0.18\right)$ (Table 4). An STEM image of P3-2 (Figure 8b) and its cross-linked derivative (Figure 8d) also revealed similar sizes and morphologies as DLS analysis and TEM. Elemental analysis performed on the corona of the micelles (Figure $\mathbf{8 b}$ and $\mathbf{8 d}$ ) revealed the presence of oxygen and silicon in addition to fluorine, which may be explained by a very thin polyimide shell. 

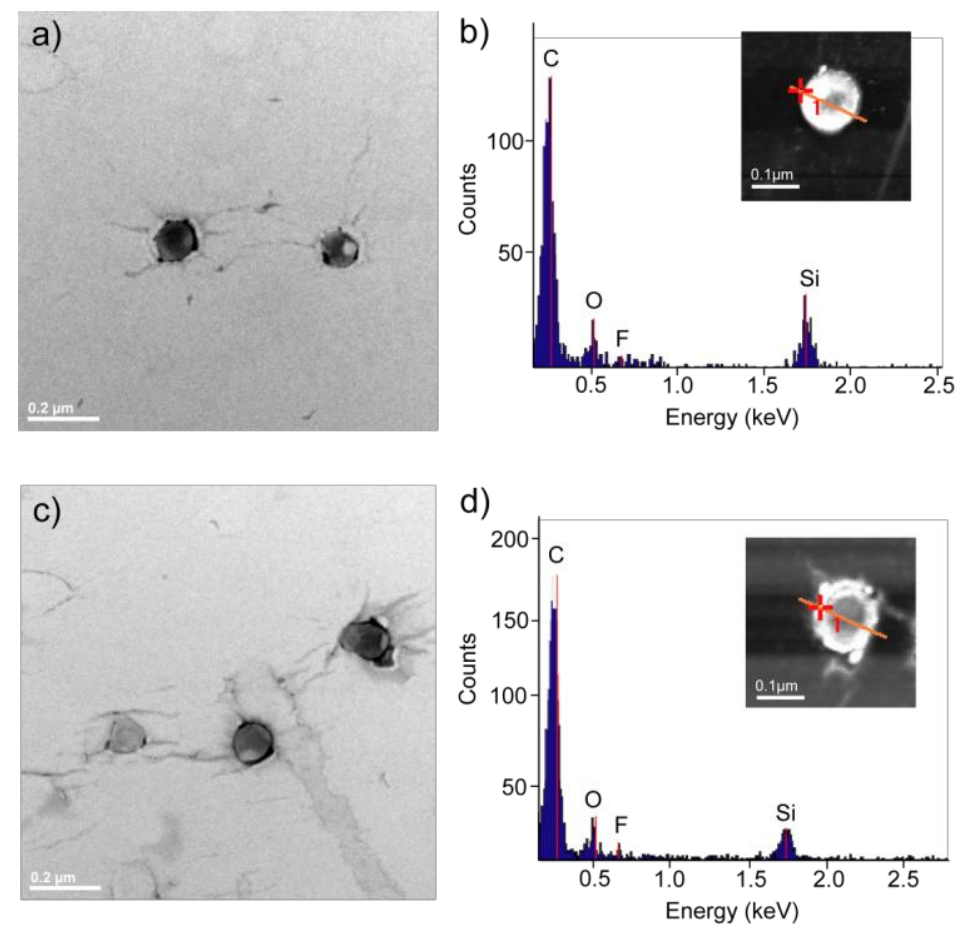

Figure 8. (a) TEM image of P3-2, (b) STEM image of P3-2 and its elemental analysis across a micelle, (c) TEM image of cross-linked P3-2 and (d) STEM image of cross-linked P3-2 and the elemental analysis across a micelle. 


\section{CONCLUSION}

In conclusion, well-defined poly(6FDA-co-TMPD) with a very high degree of $\alpha, \omega$-diamino end-groups, as determined by MALDI ToF MS and ${ }^{1} \mathrm{H}$ NMR spectroscopic analysis, was prepared via step-growth polymerization. The amine end-groups were then quantitatively functionalized with alkyl bromides to afford a telechelic macroinitiator suitable for ATRP. Subsequently, ATRP with this initiator and a PDMS-MA monomer were employed to synthesize brush triblock polyimide/poly(dimethylsiloxane) copolymers with different molecular weight P(PDMS-MA) blocks in high conversions (88-94\%). Self-assembly of these block copolymers in DMF resulted in the formation of micelles without aggregation. These micelles will adopt a 'nano-flower' shape, which were subsequently successfully cross-linked via hydrogen abstraction through the thermal degradation of BP. TEM and STEM analysis revealed that the self-assembled block copolymers and their cross-linked derivatives had spherical morphologies, consisting of a rigid/glassy PI shell, and a soft/rubbery PDMS core. The synthetic approach outlined in this study is a viable strategy to fabricate nanostructured particles with rigid/glassy PI shells and soft/rubbery PDMS cores.

\section{ASSOCIATED CONTENT}

Supporting Information. ${ }^{1} \mathrm{H}$ and ${ }^{13} \mathrm{C}$ NMR spectroscopic analysis of P1 and P2. MALDI ToF MS spectrum of $\mathbf{P 1}$ and $\mathbf{P 2}$ recorded using NaTFA and KTFA as cationisation agents.

\section{AUTHOR INFORMATION}

\section{Corresponding Author}

*E-mail: gregghq@unimelb.edu.au

\section{ACKNOWLEDGEMENT}

The authors acknowledge the funding provided by the Australian Government through the CRC Program to support this research. The authors also acknowledge the Electron 
Microscopy Unit at the Bio21 institute (The University of Melbourne) for assistance with TEM. AH acknowledges Qiang Fu for valuable discussion and Wilcent Chua for practical assistance.

\section{REFERENCES}

[1] Ghost, M. K.; Mittal, K. L. Polyimide: Fundamental and Applications; New York: Marcel Dekker; 1996.

[2] Powell, C. E.; Qiao, G. G. J. Membr. Sci. 2006; 279, 1-49.

[3] Wilson, D.; Stenzenberger, H. D.; Hergenrother, P. M. Polyimides; New York: Chapman \& Hall; 1990.

[4] Senturia, S. D. Polymers for High Technology; Washington D.C.: American Chemical Society, 1987. pp. 428-436.

[5] De Abajo, J.; de la Campa, J. Advances in Polymer Science, vol. 140. Berlin: Springer-Verlag, 1999. pp. 23-59.

[6] Hsiao, S.-H.; Yang, C.-P.; Huang, S.-C. Eur. Polym. Mater. 2004; 40, 1063-1074.

[7] Kute, V.; Banerjee, S. J. Appl. Polym. Sci. 2007; 103, 3025-3044.

[8] Chung, I. S.; Kim, S. Y. Macromolecules 2000; 33, 3190-3193.

[9] Novak, I.; Sysel, P.; Zemek, J.; Spirkova, M.; Velic, D.; Aranyosiova, M.; Florian, S.; Pollak, V.; Kleinova, A.; Lednicky, F.; Janigova, I. Eur. Polym. J. 2009; 45, 57-69.

[10] Ghosh, A.; Banerjee, S.; Komber, H.; Häußler, L.; Schneider, K.; Voit, B. Macromol. Chem. Physic. 2011; 296, 391-400.

[11] Nagase, Y.; Mori, S.; Egawa, M.; Matsui, K. Makromol. Chem-Rapid. 1990; 11, 185 191.

[12] Ku, C. K.; Lee, Y. D. Polymer 2007; 48, 3565-3573.

[13] Ghosh, A.; Banerjee, S. J. Appl. Polym. Sci. 2008; 107, 1831-1841.

[14] Arnold, C. A.; Summers, J. D.; Chen, Y. P.; Bott, R. H.; Chen, D.; McGrath, J. E. Polymer 1989; 30, 986-995.

[15] Tsai, M. H.; Chiang, P. C.; Whang, W. T.; Ko, C. J.; Huang, S. L. Surf. Coat. Tech. 2006; 200, 3297-3302.

[16] Whitesides, G. M.; Grzybowski, B. Science 2002; 295, 2418-2421.

[17] Ruzette, A. V.; Leibler, L. Nat. Mater. 2005; 4, 19-31.

[18] Fierro, D.; Buhr, K.; Abetz, C.; Boschetti-de-Fierro, A.; Abetz, V. Aust. J. Chem. 2009; 62, 885-890.

[19] Kim, J. K.; Yang, S. Y.; Lee, Y.; Kim, Y. Prog. Polym. Sci. 2010; 35, 1325-1349.

[20] Schacher, F. H.; Rupar, P. A.; Manners, I. Angew. Chem. Int. Edit. 2012; 51, 2-52.

[21] Balsara, N. P.; Tirrell, M.; Lodge, T. P. Macromolecules 1991; 24, 1975-1986.

[22] Nguyen-Misra, M.; Mattice, W. L. Macromolecules 1995; 28, 1444-1457.

[23] Saito, R.; Akiyama, Y.; Ishizu, K. Polymer 1999; 40, 655-660.

[24] Yuan, Z.; Que, Z.; Cheng, S.; Zhou, R.; Li, F. Chem. Commun. 2012; 48, 8129-8131.

[25] Saito, R.; Ishizu, K. Polymer 1997; 38, 225-229.

[26] Saito, R.; Akiyama, Y.; Tanaka, M.; Ishizu, K. Colloids Surf., A 1999; 153, 305-310.

[27] Saito, R.; Yoshida, S.; Ishizu, K. J. Appl. Polym. Sci. 1997; 63, 849-854.

[28] Kadam, V. S.; Nicol, E.; Gaillard, C. Macromolecules 2012; 45, 410-419.

[29] Siegwart, D. J.; Wu, W.; Mandalaywala, M.; Tamir, M.; Sarbu, T.; Silverstein, M. S.; Kowalewski, T.; Hollinger, J. O.; Matyjaszewski, K. Polymer 2007; 48, 7279-7290.

[30] Nanda, A. K.; Matyjaszewski, K. Macromolecules 2003; 36, 8222-8224. 
[31] Krishnan, R.; Srinivasan, K. S. V. J. Appl. Polym. Sci. 2005; 97, 989-1000.

[32] Angot, S.; Taton, D.; Gnanou, Y. Macromolecules 2000; 33, 5418-5426.

[33] Reining, B.; Keul, H.; Hocker, H. Polymer 2002; 43, 7145-7154.

[34] Majoros, I. J.; Keszler, B.; Woehler, S.; Bull, T.; Baker Jr, J. R. Macromolecules $2003 ; 36,5526-5529$.

[35] Hortin, G. L. Clin. Chem. 2006; 52, 1223-1237.

[36] Destarac, M.; Matyjaszewski, K.; Silverman, E.; Ameduri, B.; Boutevin, B.

Macromolecules 2000; 33, 4613-4615.

[37] Neugebauer, D.; Zhang, Y.; Pakula, T.; Matyjaszewski, K. Macromolecules 2005; 38, 8687-8693.

[38] Hill, D. J. T.; Preston, C. M. L.; Whittaker, A. K.; Hunt, S. M. Macromol. Symp. $2000 ; 156,95-102$.

[39] Higuchi, H.; Yamashita, T.; Horie, K.; Mita, I. Chem. Mater. 1991; 3, 188-194.

[40] Charlesby, A.; Garratt, P. G. P. Roy. Soc. Edinb. B. 1963; 273, 117-132.

[41] Charlesby, A. Proc. Roy. Soc. London A 1955; 230, 120-135.

[42] Dewhurst, H. A.; Pierre, L. E. S. J. Phys. Chem. 1960; 64, 1060-1062.

[43] Palsule, A. S.; Clarson, S. J.; Widenhouse, C. W. J. Inorg. Nucl. Chem. 2008; 18, 207-221. 